\title{
Gene Transfer in Neisseria gonorrhoeae
}

\author{
GOUR D. BISWAS, STUART A. THOMPSON, AND P. FREDERICK SPARLING* \\ Department of Microbiology and Immunology, The University of North Carolina at Chapel Hill, \\ Chapel Hill, North Carolina 27599
}

The ability of bacteria to exchange deoxyribonucleic acid (DNA) endows these organisms with greater genetic variability and increased capability to adapt to changing environments. Many bacteria have evolved transformation and conjugation systems to effect this exchange, whereas others achieve it through the action of bacteriophages. In Neisseria gonorrhoeae no transducing bacteriophages have been identified, but conjugation and transformation both occur (10). Gonococci are extremely autolytic and therefore release DNA to neighboring cells (19). Transformation with chromosomal markers has been demonstrated between strains in laboratory-grown mixed cultures (32); similar transformation probably occurs in nature. Quite recently, antigenic and phase variation of gonococcal pili has been shown to be due in large part to release of DNA from autolyzing cells, with subsequent transformation of other competent cells in the population by variant pil sequences $(32 \mathrm{a}$; C. Haas and T. Meyer, personal communication). Gonococcal transformation has been studied extensively and has proven useful in the construction of isogenic strains for mapping antibiotic resistance genes and biosynthetic auxotrophs, and in studies of molecules implicated in the virulence of this organism (10, 34). Conjugation in $N$. gonorrhoeae is important because it results in mobilization of antibiotic resistance plasmids, but chromosomal genes cannot be transferred by conjugation ( 3 , $10,27,31,37,44)$. Thus, in the laboratory and in nature, transformation is the primary means of transfer of chromosomal genes.

In this brief review, mechanisms of gene exchange will be emphasized, and some speculative comments on possible future developments are included.

\section{TRANSFORMATION}

Many bacteria are competent for the adsorption and uptake of free DNA (36). Competence is defined as the ability to take up DNA into a deoxyribonuclease-resistant form, and it usually occurs only under special environmental conditions or in certain growth phases $(7,39)$. N. gonorrhoeae is unique in that it is constitutively competent at all phases of growth. The uptake of both plasmid and chromosomal DNA by gonococci is dependent only on the presence of glucose, as well as monovalent or divalent cations, in the medium (6). Competence is restricted, however, to piliated organisms (38) or to certain organisms that produce pilin subunits (Haas and Meyer, personal communication). Loss of pili occurs readily in vitro, and most nonpiliated variants that have been studied are reduced in competence by at least a factor of $10^{4}$ compared with piliated cells $(10,21,38,39)$.

The first step in transformation is the binding of DNA to the cell surface. Although gonococci bind both homologous and heterologous DNA, only homologous DNA is taken up into a deoxyribonuclease-resistant form (14). The entry of plasmid and chromosomal DNAs appears to share an initial

\footnotetext{
* Corresponding author.
}

binding step at the cell surface, since uptake of plasmid DNA can be competitively inhibited by the presence of exogenous chromosomal DNA (18). Putative surface receptors which may be involved in the specific recognition and binding of homologous DNA have not been identified yet. The very close correlation between piliation and competence suggests that pili might be involved in DNA uptake, but there is no evidence that pili bind DNA in vitro (26). Moreover, neither purified pili nor anti-pilus antibodies block transformation by limiting concentrations of DNA (26; G. Biswas, N. Guerina, C. Brinton, and P. F. Sparling, unpublished data).

To better understand mechanisms of transformation, we have studied transformation-deficient mutants. Two mutants designated dud (DNA uptake deficient) were identified following chemical mutagenesis and are normally piliated as seen under the electron microscope but are unable to take up DNA (6a). This indicates that pili may not be sufficient for specifying DNA uptake in gonococci, although data are insufficient to rule out a minor structural change in pilin in these strains. Interestingly, Klimpel and Clark recently reported that phase variation of pili is correlated with altered expression of several cytoplasmic and membrane-bound proteins (23). It is possible that one or more of these are competence related. Further study of the dud lesion may aid in the identification of proteins involved in DNA uptake.

In addition to the differences in internalization of homologous and heterologous DNA, some gonococcal DNA sequences are internalized more efficiently than others. Graves et al. studied the uptake of fragments of pFA10, a cointegrate plasmid composed of the heterologous penicillin resistance plasmid pFA3 and the gonococcal cryptic plasmid pFA1 (18). Single $M s p I$ or TaqI restriction endonuclease fragments derived from the $\mathrm{pFA} 1$ portion of pFA10 were preferentially internalized, suggesting the presence of specific uptake sequences, as has been shown in Haemophilus influenzae $(12,16,35)$. Burnstein et al. noted that two uptake-preferred fragments of pFA1 shared a 10-base-pair (bp) sequence (5'-GATGCTCTGT-3') (9). However, this sequence was not sufficient to specify high-frequency uptake of a pBR322 derivative into which it was inserted. More recently, Goodman and Scocca identified chromosomal DNA fragments of $N$. gonorrhoeae which were able to competitively inhibit transformation (17). A 10-bp sequence (5'-GCCGTCTGAA-3') was common to such fragments and was sufficient to competitively inhibit transformation when cloned into the noncompeting pBR322. Thus, similar to the 11-bp recognition sequence responsible for DNA uptake in $H$. influenzae, there is a short DNA sequence in $N$. gonorrhoeae which appears to be involved in recognition of gonococcal DNA. It is interesting that the gonococcal recognition sequences identified by Goodman and Scocca are contained within the transcriptional termination sequences of the opaEl and immunoglobulin A protease genes, as well as three unidentified genes. This may be a general phenomenon and may suggest a mechanism by which this compo- 
nent of the DNA uptake apparatus has evolved and is preserved.

Transforming chromosomal DNA enters the gonococcal cell as a double-stranded molecule and remains principally double stranded inside the cell until homologous recombination results in transformation (8). There is no eclipse of biological activity of donor DNA during entry or for $60 \mathrm{~min}$ thereafter, which strongly favors the hypothesis that the donor DNA retains the double-stranded form, since singlestranded donor DNA has very little activity. Moreover, newly introduced DNA fractionates with labeled doublestranded DNA molecules when subjected to $\mathrm{CsCl}$ isopycnic centrifugation. In these respects also the gonococcal transformation system is similar to $H$. influenzae $(28,45)$. It is not known whether DNA enters through specialized surface structures similar to the transformasomes reported in $H$. influenzae $(1,20)$.

When circular plasmid DNA from an isogenic strain is used in transformation, a substantial proportion of the transformants contain plasmids which are either larger or smaller than the transforming plasmid. Studies with the hybrid plasmid pFA14 have helped to elucidate the mechanism by which entering plasmid DNA becomes stabilized (6). This plasmid is a 42-kilobase hybrid composed of the $\beta$-lactamase $\left(\mathrm{Ap}^{\mathrm{r}}\right)$ plasmid pFA3 and the gonococcal conjugative plasmid pFA2. Circular pFA14 ordinarily is cleaved to many small fragments during entry, and plasmids recovered from rare transformants invariably contain deletions. If the recipient contains the homologous replicon pFA2, however, pFA14 results in abundant $\mathrm{Ap}^{\mathrm{r}}$ transformants, and no deletions are observed among plasmids recovered from transformants. The ability of pFA14 to transform pFA2-containing recipients is thought to be due to marker rescue of fragmented pFA14 by the resident pFA2. Similarly, pFA10 (pFA3pFA1) transforms pFA1-containing strains at least 10-fold more efficiently than it transforms plasmid-free recipients (5). Thus, following linearization of plasmid DNA during entry and random cleavage to smaller fragments, the fragments are either religated to form deleted plasmids (an infrequent event) or rescued by homologous recombination with resident (plasmid) DNA $(4,6)$. This probably requires the gonococcal Rec function, since $\operatorname{Rec}^{-}$strains are nontransformable with plasmid (or chromosomal) DNA (24; M. Koomey, personal communication). The cleavage of entering DNA is not mediated by a restriction endonuclease, since these results were obtained in entirely isogenic backgrounds.

$N$. gonorrhoeae produces at least five different restriction enzymes and eleven different methylases $(13,25)$. A screening of 30 gonococcal isolates revealed that all but one had methylase activity, and about half produced detectable restriction enzymes (41). These restriction modification systems probably play an integral role in the survival of transforming DNA, although methylation does not affect the uptake of DNA into the cell $(9,18)$. Stein et al. showed that a plasmid (pFT180) isolated from a nonmethylating strain (WR302) was unable to transform an NgoII-producing strain (Pgh3-2), while pFT180 iscolated from Pgh3-2 transformed Pgh3-2 very well (40). Prior in vitro methylation with HaeIII methylase of pFT180 isolated from WR302 enabled this plasmid to transform Pgh3-2 with more than 1,000-fold greater efficiency. Thus, as with Escherichia coli and probably many other bacteria, $N$. gonorrhoeae appears to control the influx of DNA in part by recognizing methylation patterns and restricting those deemed to be foreign.

\section{CONJUGATION}

Plasmids̀ such as pFA3, which are not conjugally proficient, can be mobilized for conjugal transfer by 36-kilobase plasmids such as pFA2 $(2,3,10,22,30,37)$. Gonococcal conjugation mediated by pFA 2 is extremely efficient, since under optimal conditions nearly $100 \%$ of conjugation donors may transfer the $\mathrm{Ap}^{\mathrm{r}}$ plasmid $\mathrm{pFA} 3$ to recipients in a 90 -min filter mating (3). This suggests that the pFA2-mediated system is naturally derepressed. It does not appear to mobilize chromosomal markers, however. Host factors are critical in conjugal efficiency. Maximal conjugation efficiency was observed when derivatives of the gonococcal strain F62 were used as recipients. Matings between unrelated gonococcal strains often resulted in transfer efficiencies 1,000 -fold lower than those involving isogenic strains. This does not appear to be an effect of restriction modification systems, since transfer of the R-group plasmid pFT6 was relatively unaffected by restriction modification differences between the conjugation donor and recipient $(40,41)$. It is possible that the reduced efficiency of interstrain conjugation is due to differences in surface components required for stable mating pair formation.

Little is known about the physical aspects of gonococcal conjugation. Cell-to-cell contact is required; this contact does not appear to be pilus mediated, since mating pair formation is unaffected by the state of piliation (15). The presence of the 28-kilodalton form of outer membrane protein PII in either parent reduced the conjugal transfer of pFA3 (3). Other outer membrane components, which may be intimately involved in mating pair formation or in actual DNA transfer, have not been identified. In $E$. coli conjugation, DNA is transferred as a single-stranded molecule. That this may also be so in $N$. gonorrhoeae is supported by the similar mating efficiencies between isogenic strains or strains differing with respect to their restriction modification systems. Recipient restriction endonucleases would be expected to have little effect on entering single-stranded DNA.

\section{TRANSFER OF CLONED GENES INTO GONOCOCCI}

As more gonococcal genes are cloned and as techniques for the deliberate mutation of these genes in $E$. coli are developed, it becomes increasingly important to be able to return this DNA to $N$. gonorrhoeae for examination of gene function. Few studies have been published with the transformation of $N$. gonorrhoeae with gonococcal DNA cloned into $E$. coli. The first reports of success were by Koomey and colleagues, who used insertions of the bla ( $\beta$-lactamase) gene to inactivate the gonococcal $\operatorname{IgA}$ protease $(24 \mathrm{a})$ and the recA genes (24); selection for $\mathrm{Ap}^{\mathrm{r}}$ transformants resulted in allelic replacement of the wild-type gene by the mutated, cloned gene. Stein et al. used the shuttle vector pLES2 to clone a gonococcal proline-biosynthetic gene in $E$. coli; this construction transforms gonococci efficiently and exists stably, either integrated into the host chromosome or as an autonomously replicating plasmid $(42,43 ; \mathrm{G}$. Biswas and P. F. Sparling, unpublished data).

Attempts to elucidate the functions of gonococcal genes are aided by recent mutagenesis teehniques. Since transposons have not been demonstrated in gonococci, a system for introducing transposon insertions into gonococcal genes cloned into $E$. coli was developed by Seifert et al. (33). A gene encoding chloramphenicol acetyltransferase (cat) was inserted into a Tn 3 derivative lacking sequences coding for the trans-acting factors necessary to transpose. This mini- 
transposon (mTn3-cat) can be induced to insert into cloned gonococcal genes by providing transposase and resolvase functions in $E$. coli, in a vector constructed so that the great majority of viable transposon insertions occur within the cloned DNA. The resulting cat-marked DNA is then returned to the gonococcus by transformation and selection of chloramphenicol-resistant $\left(\mathrm{Cm}^{\mathrm{r}}\right)$ transformants. Transposon-mutagenized DNA replaces the wild-type chromosomal allele by homologous recombination. This allows the construction of isogenic strains, differing only in the functional presence of the gene of interest. This system, termed shuttle mutagenesis, is being used with success in several laboratories. The only other available system at present to perform similar experiments involves the use of the $\beta$-lactamase (bla) gene of $\operatorname{Tn} 3(24,24 a)$. However, cat results in significant chloramphenicol resistance when present in single copy in the gonococcal chromosome, whereas bla results in very low ampicillin or penicillin resistance; thus, $\operatorname{mTn} 3-c a t$ is preferred.

We have examined the fate of cloned gonococcal DNA when a recombinant plasmid is introduced into gonococci from $E$. coli by either transformation or conjugation. For these studies, we placed an mTn3-cat transposon adjacent to a portion of a cloned gonococcal PIA gene (11) in the shuttle vector pLES2. This plasmid (pUNCH102) can be transformed as an intact (circular) molecule from $E$. coli into gonococci or mobilized by incompatibility group $\mathrm{P}$ (IncP) plasmids such as pRK2013 for transfer into gonococci (our unpublished data). Similar conjugation experiments have been performed by others (29). The efficiency of gonococcal transformation by pUNCH102 prepared in E. coli was strain dependent. The highest efficiency of transformation was obtained with strain F62, whereas with strains FA19 and MS11 it was much lower. It is possible that this was due to differences in restriction endonucleases in these strains. Furthermore, all $\mathrm{Cm}^{\mathrm{r}}$ transformants contained pUNCH102 integrated into the host chromosome, including at least a portion of the pLES2 vector (G. Biswas, N. Carbonetti, and P. F. Sparling, unpublished data). The efficiency of pRK2013-mobilized transfer of pUNCH102 from $E$. coli also was recipient strain dependent, with F62 again being the most efficient. As many as $10 \%$ of donor $E$. coli cells transferred pUNCH102 conjugally to F62, whereas transformation resulted in much lower transfer frequencies (ca. $10^{-6}$ ). Most $\mathrm{Cm}^{\mathrm{r}}$ transconjugants contained autonomously replicating plasmids identical in size to pUNCH102, and there was little evidence for integration of insert or vector sequences into the chromosome. By probing Southern transfers of restriction digests of the transconjugants either with an oligonucleotide specific for PIA or with a probe for cat, we searched for evidence of exchange of DNA between the chromosome and the plasmid, but found no evidence of allelic exchange between plasmid and chromosomè (Biswas et al., unpublished data). Cloned gonococcal proline biosynthesis genes also have been returned to gonococcal cells by conjugation, and this therefore appears to be an attractive means of avoiding the problems caused by host restriction modification. Since conjugal transfer is very efficient, and insert DNA appears to be relatively stable on the introduced recombinant plasmid, this system may prove useful in cloning genes by mobilization of a whole library from $E$. coli into gonococci. This may be particularly useful if there is a positive selection for the gene of interest.

In addition, IncP plasmid-mediated conjugation may lead to the development of transposon mutagenesis systems within $N$. gonorrhoeae. Mutagenesis with transposons on suicide vectors via IncP conjugation has been successful in other gram-negative bacteria. A similar gonococcal system may be possible by using the easily selectable cat marker. We are constructing a chloramphenicol-resistant derivative of the transposon Tn5 (Tn5-cat) placed on a plasmid which can be mobilized into gonococci by an IncP plasmid, but which is unable to replicate in gonococci (N. Carbonetti, V. Simnad, and P. F. Sparling, unpublished data). Presumably, $\mathrm{Cm}^{\mathrm{r}}$ survivors would contain Tn5-cat transposed from the introduced plasmid into the host chromosome. It is not yet clear that this strategy will work in gonococci, but the effort is worthwhile because of the quantum leap such a system would provide for students of gonococcal biology.

When different fragments of gonococcal DNA marked by mTn3-cat prepared in E. coli were linearized and returned to gonococci by transformation, $\mathrm{Cm}^{\mathrm{r}}$ transformants were obtained at highly variable frequencies, ranging from $<10^{-9}$ to $10^{-4}$ (H. Seifert, personal communication). Whether this is due to differences in gonococcal DNA uptake sequences, cleavage by restriction enzymes, or other factors remains to be shown. It will be interesting to see whether the addition of the putative gonococcal uptake sequence identified by Goodman and Scocca (17) to inefficiently transforming cat-marked DNA has any effect on its uptake.

\section{CONCLUSIONS}

Transformation is the primary means of transfer of chromosomal genes in gonococci. Competence is generally restricted to piliated organisms. Evidence for direct involvement of pili in transformation is principally circumstantial, however. Future studies including the $d u d$ mutants should lead to identification of the protein(s) involved in DNA uptake.

The uptake of DNA in the gonococcus is specific to homologous DNA or to DNA that contains the requisite structure for uptake by competent gonococci. A 10-bp DNA recognition sequence was identified recently (17) on the basis of the ability of DNA fragments to compete for transformation by gonococcal chromosomal DNA. It remains to be determined whether this 10-bp sequence confers uptake specificity. If the 10 -bp recognition sequence is shown to increase uptake and transformation by various cloned gonococcal genes, future work may be facilitated by developing a transposon that contains the 10 -bp recognition sequence as well as an easily selectable antibiotic resistance marker.

During entry, most circular plasmid DNA is randomly cleaved and enters cells as double-stranded molecules. Subsequently the linear molecules are either religated to form plasmids or rescued by homologous recombination. In view of the fact that gonococci produce a variety of methylases and restriction enzymes, plasmid transformation in gonococci is susceptible to restriction and modification systems.

Conjugation in gonococci results in very efficient mobilization of plasmids between gonococci, but chromosomal genes cannot be transferred between gonococci. Recent work suggests that the IncP conjugal system mobilizes certain plasmids efficiently from $E$. coli into gonococci, which may prove useful in devising strategies to clone gonococcal genes by first establishing them in recombinant libraries and then mobilizing the library into gonococci, with selection for the trait of interest. 


\section{ACKNOWLEDGEMENTS}

Our unpublished studies were supported by Public Health Service grants AI15036 and AI26837 to P.F.S., both from the National Institute of Allergy and Infectious Diseases.

We thank J. Cannon, M. Koomey, T. Meyer, H. Seifert, and M. So for communication of unpublished data.

\section{LITERATURE CITED}

1. Barany, F., M. E. Kahn, and H. O. Smith. 1983. Directional integration of donor DNA in Haemophilus influenzae transformation. Proc. Natl. Acad. Sci. USA 80:7274-7278.

2. Baron, E. S., A. K. Saz, D. J. Kopecko, and J. A. Wohlhieter. 1977. Transfer of plasmid-borne beta-lactamase in Neisseria gonorrhoeae. Antimicrob. Agents Chemother. 12:270-280.

3. Biswas, G. D., E. Y. Blackman, and P. F. Sparling. 1980. High-frequency conjugal transfer of a gonococcal penicillinase plasmid. J. Bacteriol. 143:1318-1324.

4. Biswas, G. D., K. L. Burnstein, and P. F. Sparling. 1986. Linearization of donor DNA during plasmid transformation in Neisseria gonorrhoeae. J. Bacteriol. 168:756-761.

5. Biswas, G. D., J. Graves, R. Schwalbe, and P. F. Sparling. 1986. Construction of isogenic gonococcal strains varying in the presence of a 4.2-kilobase cryptic plasmid. J. Bacteriol. 167: 685-694.

6. Biswas, G. D., J. F. Graves, T. F. Sox, F. C. Tenover, and P. F. Sparling. 1982. Marker rescue by a homologous recipient plasmid during transformation of gonococci by a hybrid $\mathrm{Pc}^{r}$ plasmid. J. Bacteriol. 151:77-82.

6a.Biswas, G. D., S. A. Lacks, and P. F. Sparling. 1989. Transformation-deficient mutants of piliated Neisseria gonorrhoeae. J. Bacteriol. 171:657-664.

7. Biswas, G. D., T. Sox, E. Blackman, and P. F. Sparling. 1977. Factors affecting genetic transformation of Neisseria gonorrhoeae. J. Bacteriol. 129:983-992.

8. Biswas, G. D., and P. F. Sparling. 1981. Entry of doublestranded deoxyribonucleic acid during transformation of Neisseria gonorrhoeae. J. Bacteriol. 145:638-640.

9. Burnstein, K. L., D. Dyer, and P. F. Sparling. 1988. Preferential uptake of restriction fragments from the gonococcal cryptic plasmid by competent Neisseria gonorrhoeae. J. Gen. Microbiol. 134:547-557.

10. Cannon, J. G., and P. F. Sparling. 1984. The genetics of the gonococcus. Annu. Rev. Microbiol. 38:111-133.

11. Carbonetti, N. H., V. I. Simnad, H. S. Seifert, M. So, and P. F. Sparling. 1988. Genetics of protein 1 of Neisseria gonorrhoeae: construction of hybrid porins. Proc. Natl. Acad. Sci. USA 85:6841-6845.

12. Danner, D. B., R. A. Deich, K. L. Sisco, and H. O. Smith. 1980. An 11-base pair sequence determines the specificity of DNA uptake in Haemophilus transformation. Gene 11:311-318.

13. Davies, J. K. 1989. DNA restriction and modification systems in Neisseria gonorrhoeae. Clin. Microbiol. Rev. 2(Suppl.):S35S40.

14. Dougherty, T. F., A. Asmus, and A. Tomasz. 1979. Specificity of DNA uptake in genetic transformation of gonococci. Biochem. Biophys. Res. Commun. 86:97-104.

15. Eisenstein, B. I., T. Sox, G. Biswas, E. Blackman, and P. F. Sparling. 1977. Conjugal transfer of the gonococcal penicillinase plasmid. Science 195:998-1000.

16. Goodgal, S. H. 1982. DNA uptake in Haemophilus transformation. Annu. Rev. Genet. 16:169-192.

17. Goodman, S. D., and J. J. Scocca. 1988. Identification and arrangement of the DNA sequence recognized in specific transformation of Neisseria gonorrhoeae. Proc. Natl. Acad. Sci. USA 85:6982-6986.

18. Graves, J. G., G. D. Biswas, and P. F. Sparling. 1982. Sequencespecific DNA uptake in transformation of Neisseria gonorrhoeae. J. Bacteriol. 152:1071-1077.

19. Hebeler, B. H., and F. E. Young. 1975. Autolysis of Neisseria gonorrhoeae. J. Bacteriol. 122:385-391.

20. Kahn, M. E., G. Maul, and S. H. Goodgal. 1982. Possible mechanism for donor DNA binding and transport in Haemophilus. Proc. Natl. Acad. Sci. USA 79:6370-6374.
21. Kellogg, D. S., Jr., W. L. Peacock, Jr., W. E. Deacon, L. Brown, and C. I. Pirkle. 1963. Neisseria gonorrhoeae. I. Virulence genetically linked to colony variation. J. Bacteriol. 85:1274 1279.

22. Kirvin, L. A., and C. Thornsberry. 1977. Transfer of betalactamase genes of Neisseria gonorrhoeae by conjugation. Antimicrob. Agents Chemother. 11:1004-1006

23. Klimpel, K. W., and V. L. Clark. 1988. Multiple protein differences exist between Neisseria gonorrhoeae type 1 and type 4. Infect. Immun. 56:808-814.

24. Koomey, J. M., and S. Falkow. 1987. Cloning of the recA gene of Neisseria gonorrhoeae and construction of gonococcal recA mutants. J. Bacteriol. 169:790-795.

24a.Koomey, M. J., R. E. Gill, and S. Falkow. 1982. Genetic and biochemical analysis of gonococcal IgAl protease; cloning in Escherichia coli and construction of mutants of gonococci that fail to produce the activity. Proc. Natl. Acad. Sci. USA 79: 7881-7885.

25. Korch, C., P. Hagblom, and S. Normark. 1983. Sequencespecific DNA modification in Neisseria gonorrhoeae. J. Bacteriol. 15:1324-1332.

26. Mathis, L., and J. J. Scocca. 1984. On the role of pili in transformation of Neisseria gonorrhoeae. J. Gen. Microbiol. 130:3165-3173.

27. Norlander, L., J. Davies, and S. Normark. 1979. Genetic exchange mechanisms in Neisseria gonorrhoeae. J. Bacteriol. 138:756-761.

28. Notani, N., and S. H. Goodgal. 1965. On the nature of recombinants formed during transformation in Haemophilus influenzae. J. Gen. Physiol. 49:197-209.

29. Piffaretti, J.-C., A. Arini, and J. Frey. 1988. pUB307 mobilizes resistance plasmids from $E$. coli into Neisseria gonorrhoeae. Mol. Gen. Genet. 212:215-218.

30. Roberts, M., and S. Falkow. 1977. Conjugal transfer of R plasmids in Neisseria gonorrhoeae. Nature (London) 266:630631.

31. Roberts, M., and S. Falkow. 1978. Plasmid-mediated chromosomal gene transfer in Neisseria gonorrhoeae. J. Bacteriol. 134:66-70.

32. Sarubbi, F. A., Jr., and P. F. Sparling. 1974. Transfer of antibiotic resistance in mixed cultures of Neisseria gonorrhoeae. J. Infect. Dis. 130:660-663.

32a.Seifert, H. S., R. S. Ajioka, C. Marchal, P. F. Sparling, and M. So. 1988. DNA transformation leads to pilin antigenic variation in Neisseria gonorrhoeae. Nature (London) 336:392-395.

33. Seifert, H. S., M. So, and F. Heffron. 1986. Shuttle mutagenesis: a method of introducing transposons into transformable organisms, p. 123-134. In J. K. Setlow, and A. Hollander (ed.), Genetic engineering principles and methods, vol. 8. Plenum Publishing Corp., New York.

34. Shockley, T. E. 1984. Genetic loci of the gonococcus (Neisseria gonorrhoeae), p. 162-168. In S. J. O'Brien (ed.), Genetic maps 1984, vol. 3. Cold Spring Harbor Laboratory, Cold Spring Harbor, N.Y.

35. Sisco, K. L., and H. O. Smith. 1979. Sequence-specific DNA uptake in Haemophilus transformation. Proc. Natl. Acad. Sci. USA 76:972-976.

36. Smith, H. O., D. B. Danner, and R. A. Deich. 1981. Genetic transformation. Annu. Rev. Biochem. 50:41-68.

37. Sox, T. F., W. Mohammed, E. Blackman, G. Biswas, and P. F. Sparling. 1978. Conjugative plasmids in Neisseria gonorrhoeae. J. Bacteriol. 134:278-286.

38. Sparling, P. F. 1966. Genetic transformation of Neisseria gonorrhoeae to streptomycin resistance. J. Bacteriol. 92:1364-1371.

39. Sparling, P. F., G. D. Biswas, and T. E. Sox. 1977. Transformation of the gonococcus, p. 155-176. In R. B. Roberts (ed.), The gonococcus. John Wiley \& Sons, Inc., New York.

40. Stein, D. C., S. Gregoire, and A. Piekarowicz. 1988. Restriction of plasmid DNA during transformation but not conjugation in Neisseria gonorhoeae. Infect. Immun. 56:112-116.

41. Stein, D. C., S. T. Gregoire, and A. J. Piekarowicz. 1988. Role of restriction and modification on genetic exchange in Neisseria gonorrhoeae, p. 323-327. In J. T. Poolman, H. C. Zaner, T. F. 
Meyer, J. E. Heckels, P. R. H. Makela, H. Smith, and E. C. Beuvery (ed.), Gonococci and meningococci. Kluwer Academic Publishers, Dordrecht, The Netherlands.

42. Stein, D. C., L. E. Silver, V. L. Clark, and F. E. Young. 1983. Construction and characterization of a new shuttle vector, pLES2, capable of functioning in Escherichia coli and Neisseria gonorrhoeae. Gene 25:241-247.

43. Stein, D. C., L. E. Silver, V. L. Clark, and F. E. Young. 1984.
Cloning genes for proline biosynthesis from Neisseria gonorrhoeae: identification by interspecific complementation of Escherichia coli mutants. J. Bacteriol. 158:696-700.

44. Steinberg, V. I., and I. D. Goldberg. 1980. On the question of chromosomal gene transfer via conjugation in Neisseria gonorrhoeae. J. Bacteriol. 142:350-354.

45. Stuy, J. H. 1965. Fate of transforming DNA in the Haemophilus influenzae transformation system. J. Mol. Biol. 13:554-570. 